\title{
Research on 3D Simulation Modeling Method of Faults Based on Coal Stratum Floor TIN
}

\author{
http://dx.doi.org/10.3991/ijoe.v10i3.3688 \\ Yachun Mao, Defu Che, Yongsheng Chen \\ Northeastern University, Shenyang, Liaoning Province, China
}

\begin{abstract}
The research on 3D simulation technology for complex geological body according to geological and remote sensing data is a hot issue in current geosciences research field. The simulation and expression of coal mine structures containing faults are the main bottleneck. A new 3D interactive simulation modeling method is proposed and a relevant code is developed for the method. By using the system, the fault data can be gained from the coal stratum floor triangulated irregular network (TIN) interactively, and the 3D solid models of the fault are generated according to the results of computing the fault/coal seam intersection line, fault modeling centre lines and fault modeling influence domains. Moreover, the floor contours of coal stratum including faults can be updated quickly and accurately, which lay the foundation for precise modeling of coal body and digital mine construction.
\end{abstract}

Index Terms-3D fault simulation modeling, three-dimensional interactive, coal stratum floor, triangulated irregular network (TIN), remote sensing data

\section{INTRODUCTION}

With the development of visualization in scientific computing and the computer simulation technology of geological information, many researchers have pay attention to the 3D structure of complex geologic body in 3D geosciences simulation, which gradually becomes a hot issue in the field of research and application of digital geology, mining, GIS and remote sensing method etc, where the simulation and expression of fault structures in geological body is the major bottleneck in 3D simulation technology of complex geologic body ${ }^{[1-8]}$. Currently, a number of domestic and foreign scholars have put forward some methods of 3D fault modeling recently. According to the data source, there are several modeling methods: modeling method based on borehole data ${ }^{[9]}$, and modeling method with combination of wells and shock ${ }^{[10]}$. According to the different expressions of faults, there are modeling method based on wireframe model ${ }^{[11]}$, and 3D interactive modeling method based on GTP '[12] etc. However, many difficulties and shortcomings still exist in the application of these methods, mainly reflected in the following aspects:

1. The methods flexibly adding the data of fault point are less elaborated, resulting in insufficient data for fault modeling, and the later work of interpretation and processing for fault will be very difficult.

2. The methods mentioned above cannot mathematically describe and express the faults accurately because the relationship between faults and their spatial existing forms are completed and changeable, especially in the condition of complexity of fault system containing cross-cutting faults.

3. The discontinuities of stratum caused by fault structure lead to the difficulties of interpolation, and manual modification will be cumbersome in the next processing of stratum, which is not suitable for automatic or semi-automatic modeling of computer.

This paper proposes a 3D interactive fault modeling method in view of the above questions based on the coal stratum floor TIN to solve the key problems of data acquisition, 3D fault modeling and automatic contour drawing.

\section{BASIC PRINCIPLE OF 3D SIMULATION FAULT MODELING}

For the convenience of fault modeling, fault/coal stratum intersection line (FCSIL) is classified into two kinds. The one on the side of the handing wall is called upper fault/coal stratum intersection line (UFCSIL) and the other on the side of the footwall is called lower fault/coal stratum intersection line (LFCSIL). Meanwhile, two concepts containing "fault/coal stratum centerline" and "fault influence domain" are introduced and are defined as follows:

Definition 1: The middle line between UFCSIL and LFCSIL is called fault/coal stratum centerline (FCSCL).

Definition 2: The area composed of triangles of coal stratum floor TIN intersected or surrounded by FCSIL is called fault influence domain (FID). The boundary of FID is divided into upper/lower boundary of FID and referred to as upper/lower boundaries for short according to the dividing principle of FCSIL.

As shown in Figure 1, three main modeling processes are included. They are generation of the coal stratum floor TIN, acquisition of fault data and fault modeling.

\section{GENERATION OF COAL STRATUM FLOOR TIN}

According to Delaunay criterion, coal stratum floor TIN is generated from the discrete points of coal stratum floor contours and then the borehole points on the coal stratum are inserted into the TIN. Because the continuous triangle generated by Delaunay criterion is unique, and has the empty-circle and the max-min angle characteristics, it can express complex surface accurately, and has the best terrain simulation effect ${ }^{[13,14]}$. The accurate fault points needed for $3 \mathrm{D}$ interactive process can be obtained on the basis of the coal stratum floor TIN. 


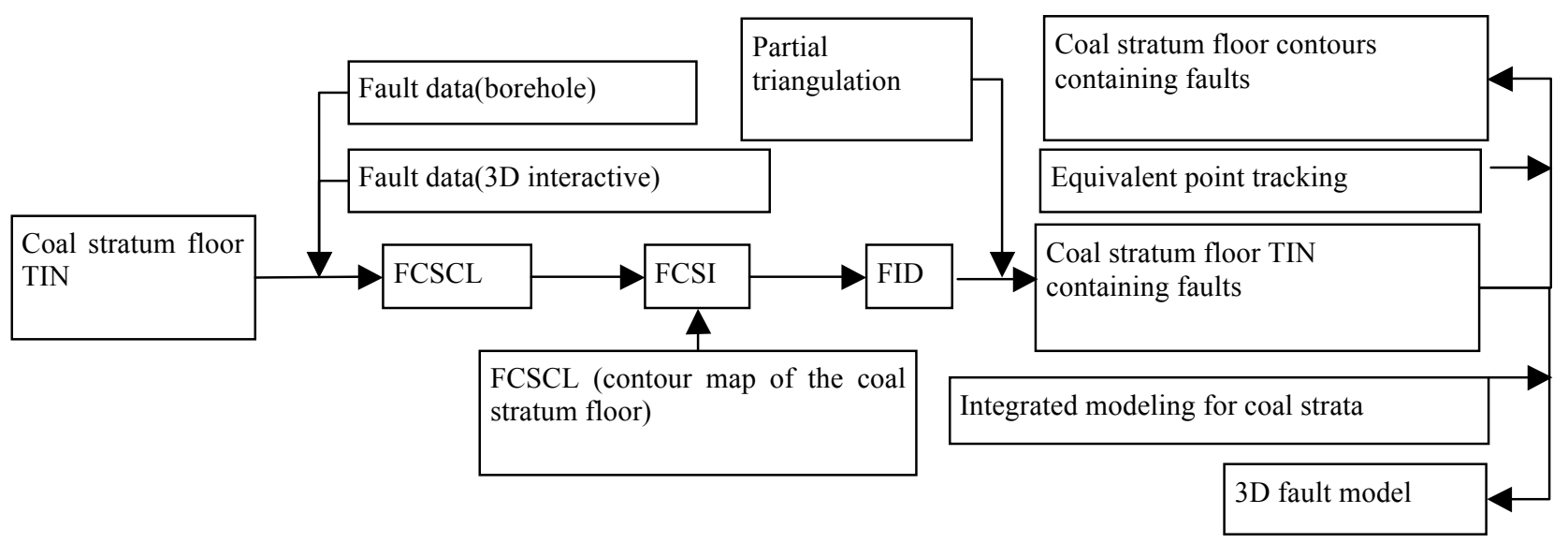

Figure 1. The process of fault modeling

\section{3D SIMULATION MODELING METHOD ACCORDING TO GEOLOGICAL AND REMOTE SENSING DATA}

In the practical production process of the coal mine, under the condition that the overall outline of faults in geological body is unknown, based on geological and remote sensing data, the $3 \mathrm{D}$ coordinates of fault points are obtained through the interactive picking on the coal floor TIN as shown in Figure 2. These data are directly used for modeling the fault which has very strong practicability by adding the geometry attributes of the fault points. The definition of data format of fault point is shown in Table 1.

In the method of obtaining fault point interactively, first the $2 \mathrm{D}$ coordinates of the fault points are transformed into the $2 \mathrm{D}$ coordinates $\mathrm{x}$ and $\mathrm{y}$ through the OpenGL matrix. According to the value of $\mathrm{x}$ and $\mathrm{y}$, the triangular facet where the vertical projection of the point locates on the coal TIN is determined, and the elevation of the point is calculated by means of the coordinates of three vertices of the triangular facet, 3D data sources is gained for 3D simulation modeling. The interactive picking up fault points is more convenient because the points on the triangular facet move with the moving of mouse in this obtaining process.

\section{MODELING THE FAULT}

\section{A. Calculation of the FCSCL}

When all the fault points data of one fault have been stored in dynamic array $f$, the main algorithm of calculating the FCSCL can be described as follows:

Step 1: cycling $f$, calculating the azimuth of the line between each fault point and the other fault points, calculating the absolute value of the difference between the maximum and minimum azimuth, and marking the fault point with the smallest absolute value as $p_{1}$.

Step 2: moving $p_{1}$ to the empty dynamic array $\mathrm{g}$ from $f$, cycling the remaining points of $f$, finding the point nearest to $p_{1}$ and marking it as $p_{2}$ and moving it to $g$, then finding the point nearest to $p_{2}$ from $f$, repeating the cycle above until no points remained in $f$.

Step 3: cycling $g$, calculating the projection points coordinates on the coal stratum floor TIN for each fault point along the tendency angle and the dip angle, replacing the fault points coordinates with its projection points coordinates.

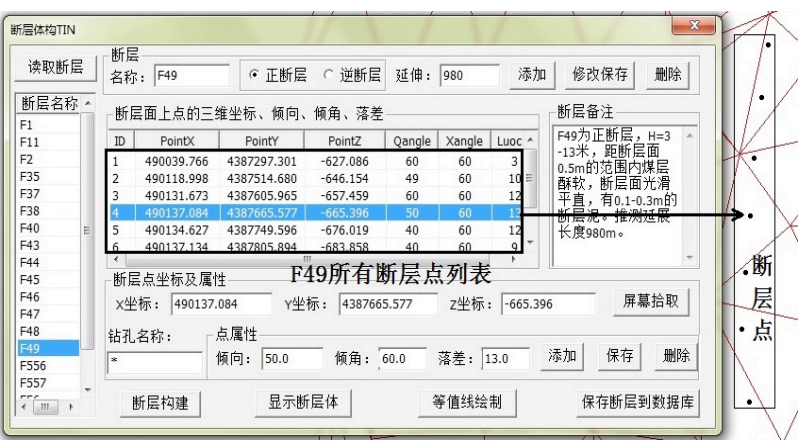

Figure 2. Picking up fault point interactively (The version is designed for Chinese)

TABLE I.

THE DEFINITION OF DATA FORMAT OF FAULT POINT

\begin{tabular}{|c|c|c|}
\hline $\begin{array}{l}\text { Field } \\
\text { name }\end{array}$ & $\begin{array}{l}\text { Data } \\
\text { type }\end{array}$ & Explanation \\
\hline $\begin{array}{l}\text { FaultName } \\
\text { PointID } \\
\text { PointX } \\
\text { PointY } \\
\text { PointZ } \\
\text { Qangle } \\
\text { Xangle } \\
\text { Luocha } \\
\text { FaultType } \\
\text { Extend }\end{array}$ & $\begin{array}{l}\text { Char } \\
\text { Long } \\
\text { Double } \\
\text { Double } \\
\text { Double } \\
\text { Float } \\
\text { Float } \\
\text { Float } \\
\text { Bool } \\
\text { Char }\end{array}$ & $\begin{array}{l}\text { Fault name } \\
\text { Ordinal number of point } \\
\text { X-coordinate } \\
\text { Y-coordinate } \\
\text { Zcoordinate } \\
\text { Fault dip } \\
\text { Fault dip angle } \\
\text { Fault fall value } \\
\text { Fault type } \\
\text { Fault extension. thickness } \\
\text { etc. }\end{array}$ \\
\hline
\end{tabular}

Step 4: assuming that there are $\mathrm{n}$ fault points in $\mathrm{g}$ and they are $p_{1}, p_{2} \ldots, p_{\mathrm{n}-1}$, pn respectively, connecting points $p_{2}, p_{1}$ and $p_{\mathrm{n}-1}, \mathrm{pn}$, inputting the length of extending line of segments $p_{2} p_{1}$ and $p_{\mathrm{n}-1} p_{\mathrm{n}}$, then calculating coordinates of the end points to get the tendency angle and dip angle of two endpoints.

Step 5: calculating projection points coordinates of the end points on the coal stratum floor TIN along the tendency angle and dip angle. If the projection points does not exist, the extension line must have 2D intersection with coal stratum boundary, calculating $x$-coordinate and $\mathrm{y}$-coordinate of intersection points and getting $\mathrm{z}$ -coordinate by elevation interpolation of two endpoints of the intersecting edges, then computing fall value by 
distance interpolation through the fall value of $\mathrm{p} 2$, $\mathrm{p} 1$ (or $\mathrm{pn}-1, \mathrm{pn})$. If the projection point exists, the fall value is 0 .

Step 6: inserting two endpoints calculated into the first and last of $g$ respectively, and connecting all the points in $\mathrm{g}$ in sequence to obtain one FCSCL.

\section{B. Determination of the FCSIL and FID}

FID is determined by FCSIL, and the coordinates of points on FSCIL are computed by means of a series of fault points on FCSCL according to (1).

$$
\left\{\begin{array}{l}
\mathrm{X}=\sin \left(\mathrm{a}_{2}\right) \times(\mathrm{h}-\mathrm{z}) / \tan \left(\mathrm{a}_{1}\right)+\mathrm{x} \\
\mathrm{Y}=\cos \left(\mathrm{a}_{2}\right) \times(\mathrm{h}-\mathrm{z}) / \tan \left(\mathrm{a}_{1}\right)+\mathrm{y}
\end{array}\right.
$$

where $x, y, z$ are coordinate value of fault point known. $\mathrm{h}$ is height $(\mathrm{h}=\mathrm{Z}+\mathrm{lc} / 2$ when the point relatively moves upward, and $\mathrm{h}=\mathrm{z}-\mathrm{lc} / 2$ when the point relatively moves downward, lc being fault fall value), a1 is fault dip angle, a2 is fault tendency angle .

There are two treatments in the process of connecting FCSIL to form FID.

(1) As shown in Fig. 3a, p0 is the point of intersection of FID and coal stratum boundary. p1 and p2 are the points of FCSIL by (1), p3 and p4 are two endpoints of coal stratum boundary edge. As shown in Fig.3b, boundary edge p3p4 is deleted and edge p1p3 and p2p4 are connected. As shown in Fig.3c, another unclosed end is treated the same way above, and then FID and upper/lower boundaries are obtained.

(2) As shown in Fig.4a, p0 is pinch-out point, p1, p2, p3 are three vertices of the triangle where p0 locates. As shown in Fig.4b, triangle p1p2p3 is deleted, edges p0p1, p0 p2, p0 p3 are connected, and then three new triangles are reconstructed. As shown in Fig.4c, triangles in FID are deleted, so upper/lower boundaries are determined.

\section{Partial triangulation of the fault}

As shown in Fig.5a, if the fault is a normal fault, the partial triangulation is used as an area surrounded by upper boundary and UFCSIL and an area surrounded by lower boundary and LFCSIL respectively. If the fault is a reverse fault, the partial triangulation as is shown in Fig.5b, is used for an area surrounded by upper boundary and LFCSIL and an area surrounded by lower boundary and UFCSIL respectively.

Let the point-group of UFCSIL, LFCSIL be up $(i)$, $d n(i)$, and the point-group of upper boundary and lower boundary be $b u(i)$ and $b d(i), i=1,2, \ldots, n . n$ is the number of point-group elements. $b u()$ and $b d()$ don't contain pinch-out point and the triangulation algorithm (taking normal fault as example) is described as follows:

Step 1: selecting point $i$ and point $i+1$ from $u p()$, if $i=1$, making $L=1$ to find point $k$ beginning from $L$ in $b u()$, if the connection angle of point $\mathrm{i}, \mathrm{i}+1$ and $\mathrm{k}$ is the biggest and the newly generated edges $b u(k) u p(i), b u(k) u p(i+1)$ have no intersection with upper boundary, adding triangle $u p(i) b u(k) u p(i+1) ; \quad$ if $\quad k>L, \quad$ adding triangle $b u(j) u p(i) b u(j+1), j=L, \ldots, k$, if $k-L \geq 2$, exchanging the diagonal for $b u(j) u p(i) b u(j+1), L=k$.

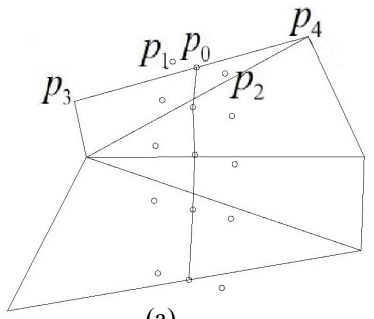

(a)

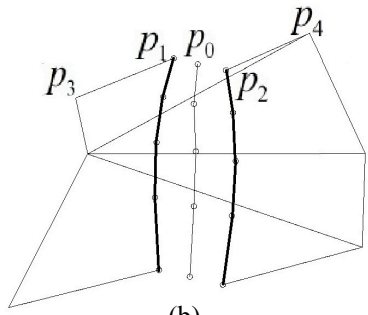

(b)

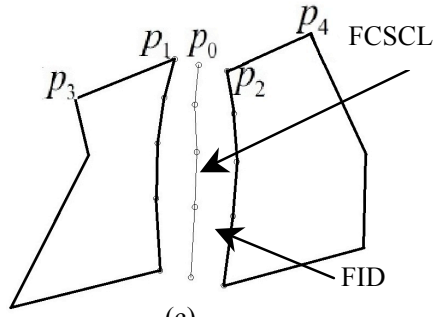

(c)

Figure 3. Intersection of fault and coal stratum boundaries

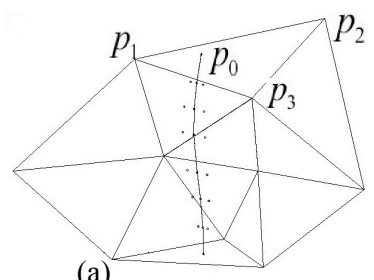

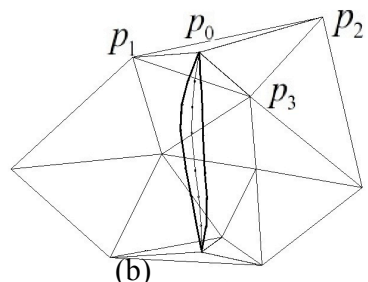

(b)

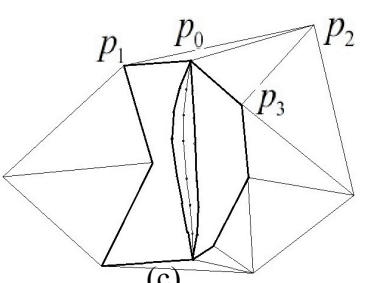

(c)

Figure 4. Reconstruction of triangles with pinch-out point

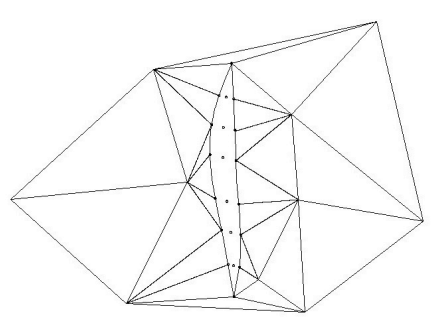

(a) Normal fault

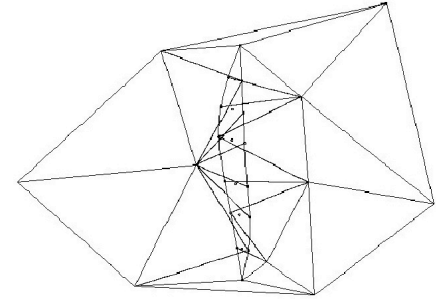

(b) Reverse fault

Figure 5. Partial triangulation for fault 
PAPER

Step 2: repeating step1 until there is no remaining point in UFCSIL, if $k<n$, adding triangle $b u(j) u p(n) b u(j+1), j=k, \ldots, n$, if $n-k \geq 2$, exchanging the diagonal for $b u(j) u p(n) b u(j+1)$.

Step 3: beginning from creating triangles by connecting points from $d n()$ and $b d()$, repeating step1 and step2, to finish the triangulation for area on the side of LFCSIL.

\section{Treatment of fault intersection}

When modeling the fault, the current fault intersects the previous fault (see in Fig.6) if FCSCL of the current fault intersects FCSIL of the previous fault. At this time, the FCSIL intersected the previous fault is treated as the coal stratum boundary if there is only one intersecting point, the current fault becomes a new fault in which the end on the side of intersecting point is not closed. If there are two intersecting points, the current fault changes into two new faults that must have one end not closed, and then they are dealt with separately. If there exist reverse fault in intersecting faults, the first fault must be firstly judged no matter normal or reverse because there is a overlap in reverse fault horizontal projection zone.

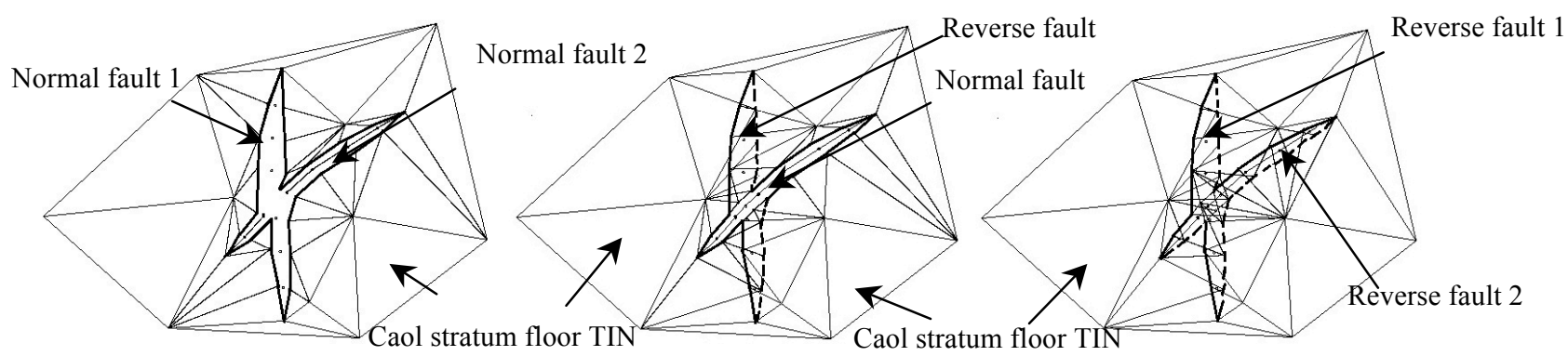

(a) Normal-normal intersection

(b) Normal-reverse intersection

(c) Reverse-reverse intersection

Figure 6. Fault intersection

\section{DISPLAYING OF FAULT MODEL AND CONTOUR} MAPPING

One fault may intersect with many coal strata, after calculating the FCSIL of the fault in each intersecting coal stratum, triangulation algorithm is used to suture UFCSIL or LFCSIL on two adjacent coal strata of the same fault, building multiple TIN, and then the fault body surface is connected up and down (without regarding the fault thickness). According to the actual situation, a complete fault body model will be developed after entering the upper and lower end elevation of the fault.

In this paper, the contours are generated automatically by using the method of equivalent point tracking based on coal stratum floor TIN, because TIN has concerned the terrain factors and stored the topological relationships between points, not only the resulted contours have higher accuracy which could meet the needs of various analyses and mapping, but also there is a high generating efficiency. The elevation of contours is marked at the intersection of straight lines and contour lines by means of line drawing, fault annotations, including the name, tendency angle, dip angle of the fault, are added manually.

\section{EXPERIMENT RESULTS}

In the Windows environment, a software system GeoMS 3D for fault 3D modeling interactively and contour drawing automatically is developed using $\mathrm{VC}++$ and OpenGL based on coal stratum floor TIN. Using this software, the boreholes, contours and fault data on multiple coal strata are extracted in the surrounding area of a fault. The 3D modeling for single fault on multiple coal strata is completed at the same time, thus automatic drawing for contours of multiple coal strata is realized, and the convenience and reliability of the method described above is verified. Fig.7a is a comprehensive display of coal stratum models, boreholes, ground, industrial square and underworkings models. Fig.7b shows the fault and coal stratum models that have been cut. Fig. $8 \mathrm{a}$ is the coal stratum floor TIN generated by the contours and borehole data. Fig. $8 \mathrm{~b}$ is the coal stratum floor contours generated automatically from CD-TIN containing faults. Fig. $8 \mathrm{c}$ shows the cutting line, faults, and its annotation. Fig. $8 \mathrm{~d}$ is a two-dimensional profile of single fault and multiple coal strata.
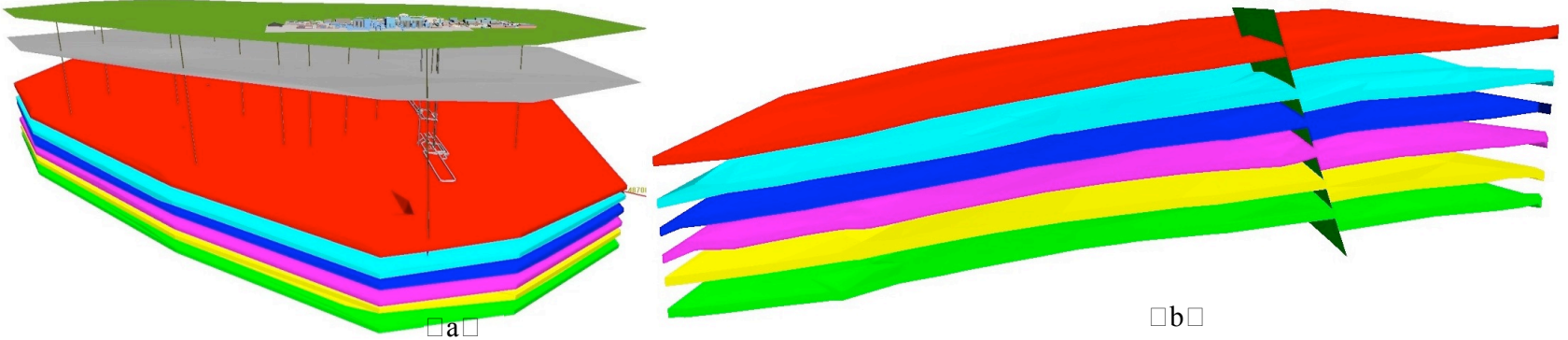

Figure 7. 3D display for models 

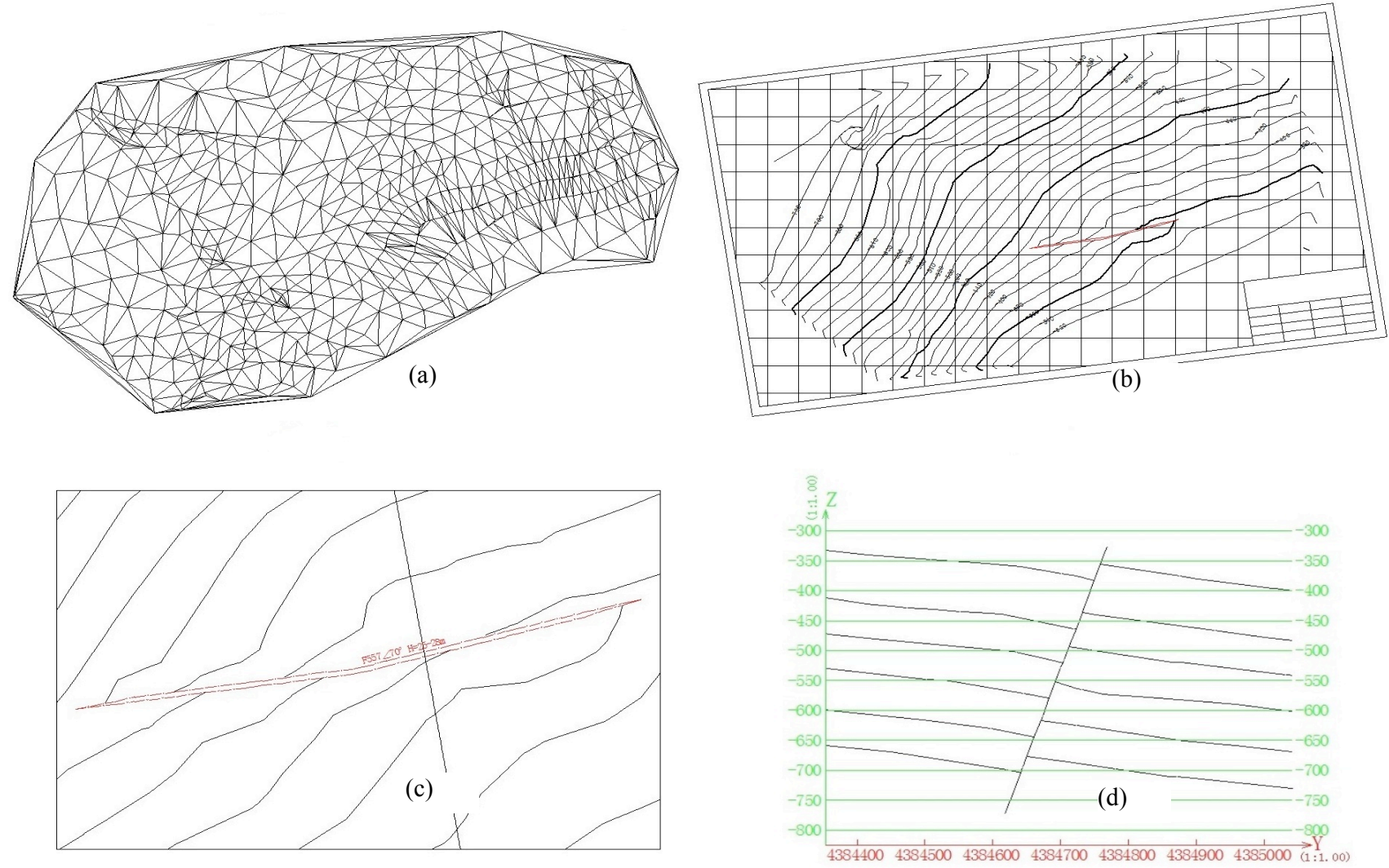

Figure 8. 2D display for models

\section{CONCLUSIONS}

A 3D interactive fault modeling method based on coal stratum floor TIN is presented. The main conclusions are as follows.

(1) The fault point data is added interactively which can enrich the data source for fault modeling.

(2) The method proposed in this paper is applied to construct the fault model by adding the artificial geological knowledge and it has improved the precision of modeling.

(3) The method proposed in this paper can update the coal floor contour quickly and accurately.

\section{REFERENCES}

[1] R.F. De, P Oreste, S Pelizza, "Subsurface geological-geotechnical modelling to sustain underground civil planning," Engineering

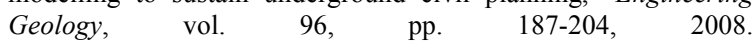
http://dx.doi.org/10.1016/j.enggeo.2007.11.002

[2] O. Kaufmann, T. Martin, "3D geological modeling from boreholes, cross-sections and geological maps, application over former natural gas storages in coal mines," Computers and Geosciences, vol. $34, \quad$ pp. 2008. http://dx.doi.org/10.1016/j.cageo.2007.09.005

[3] K. Matthias, "Visualization of geographically related multidimensional data in virtual 3D scenes," Computers and Geosciences, vol. 26, pp. 101-108, 2000. http://dx.doi.org/10.1016/S0098-3004(99)00036-9

[4] N.D. Deng, E.K. Hou, Z.H. Zhang, "An Improvent of 3D OO-Solid Model," The International Archives of the Photogrammetry, Remote Sensing and Spatial Information Sciences, Beijing, vol. XXXVII, Part B4, 2008.

[5] J.Y. Gong, P.G. Cheng, Y.D.Wang, "Three-dimensional modeling and application in geological exploration engineering," Computers and Geosciences, vol.30, pp. 391-404, 2004. http://dx.doi.org/10.1016/j.cageo.2003.06.003

[6] D.F. Che, L.X. Wu, Z.R. Yin, "The new method for creating 3D model automatically of bad break within geological body," Journl of China Coal Society, vol. 34, pp. 1305-1309, 2009.

[7] J.V. Kumar, M. Mukherjee, "Scope of Building Information Modeling (BIM) in India," Journal of Engineering Science \& Technology Review, vol. 2, pp. 165-169, 2009.

[8] Y.I. Kuchin, R.I. Muhamedyev, E.L. Muhamedyeva, et al, "The analysis of the data of geophysical research of boreholes by means of artificial neural networks," Computer Modelling and New Technologies, vol. 15, pp. 35-40, 2011.

[9] X.X. Chen, L.X. Wu, D.F. Che, et al, "3D modeling method of geological bodies including faults based on borehole data," Coal Geology \& Exploration, vol. 33, pp. 5-8, 2005.

[10] L.C. Qu, C.R. Bian, "Application of fault modeling combined with well data and seismic data in complicated fault block," Fault-Block Oil \& Gas Field, vol. 19, pp. 426-429, 2012.

[11] L.F. Zhu, G.L. Chen, X.C. Wu, et al, "3D geological fault model and its construction based on wire-frame model," Earth Science Frontiers (China University of Geosciences(Beijing, Peking University)), vol. 14, pp. 277-281, 2007.

[12] D.F. Che, L.X. Wu, Z.R. Yin, et al, "On the GTP-Based 3D Interactive Modeling Method for Geological Faults," Journal of Northeastern University(Natural Science), vol. 29, pp. 395-398, 2008.

[13] V.J.D. Tsai, "Delaunay Triangulations in TIN Creation: an Overview and a Linear-time Algorithm," International Journal of Geographical Information System, vol. 7, pp. 501-524, 1993. http://dx.doi.org/10.1080/02693799308901979

[14] X.J. Liu, J.Y. Gong, "Delaunay Triangulation of Constrained Data Set," Acta Geodaetica Et Cartographic Sinica, vol. 30, pp. 82-83, 2001. 


\section{AUTHORS}

Yachun Mao is a professor in Institute for Geo-informatics \& Digital Mine Research, Northeastern University, China. His research interests include theories and key technologies of digital mining, 3d geological modeling, and the technology of $3 \mathrm{~S}$ integration, mine surveying and mapping technology. (E-mail: dbdxmyc@163.com)

Defu Che is a professor in Institute for Geo-informatics \& Digital Mine Research, Northeastern University, China. His research interests include the principles and algorithms of Geographic Information System (GIS), theories and key technologies of digital mining, digital city, 3d geological modeling, and the technology of $3 \mathrm{~S}$ integration, software development, mine surveying and mapping technology. (E-mail:chedefu@mail.neu.edu.cn)
Yongsheng Chen is a professor in Institute for Geo-informatics \& Digital Mine Research, Northeastern University, China. His research interests include the principles and algorithms of Geographic Information System (GIS), 3d geological modeling, and the technology of $3 \mathrm{~S}$ integration, mine surveying and mapping technology. (E-mail:chenyongsheng@mail.neu.edu.cn)

This research presented in this paper has been supported jointly by National Natural Science Foundation (NNSF) of China (41371437, 51179031), Projects of International Cooperation and Exchanges NSFC (51250110531, 51350110534), Major State Basic Research Development Program (2013CB227902), State Key Laboratory of Geohazard Prevention and Geoenvironment Protection (SKLGP2012K009), and "985 Project" of Northeastern University, China. All of them are gratefully acknowledged. Submitted 21 March 2014. Published as re-submitted by the authors 28 April 2014. 